\title{
ESTEREOTIPIA E PLASTICIDADE NA SEQÜÊNCIA PREDATÓRIA DE THERIDION EVEXUM KEYSERLING 1884 (ARANEAE: THERIDIIDAE)
}

\author{
Carolina Ribeiro Martins Garcia \& Hilton Ferreira Japyassú
}

\author{
Biota Neotropica v5(n1a) - http://www.biotaneotropica.org.br/v5n1a/pt/abstract?article+BN001051a2005 \\ Recebido em 07/12/2003 \\ Aceito em 01/02/2005
}

Instituto Butantan, Laboratório de Artrópodes, Av. Vital Brasil, 1500 - Cep: 05503-900, São Paulo-SP, Brasil. E-mail:carolgarcia@butantan.gov.br, japyassu@butantan.gov.br

\begin{abstract}
Web-spiders' foraging behaviour starts with the selection of a suitable site for web construction. The predatory sequence is initiated following spider contact with or receipt of some stimulus from a potential prey. The sequence continues with an approach or pursuit followed by attack and capture of the prey item; spider predatory behaviour shows varying degrees of plasticity. The present study describes the web of Theridion evexum (Theridiidae), and its predatory sequence upon the ant Atta sp. and Tenebrio molitor beetle larvae. The level of stereotypy present in the predatory sequences of $T$. evexum was evaluated and compared with other three theridiid species. The predatory sequences of $T$. evexum were taperecorded, transferred from the camera to a computer and analyzed with the assistance of EthoSeq, resulting in an ethogram for each of the prey types, and in a list of behavioural routines. The web of T. evexum has viscid elements all around. The selection of microhabitat with high humidity levels could be adaptive in this species, since the humidity conserves the viscid thread properties for a longer period of time, and thus reduces energy expenditures due to thread reposition. Preying upon ants requires more bites and partial transports than preying upon tenebrio larvae. This suggests that the immobilization of the ant is more difficult than the beetle larvae immobilization. The predatory behaviour is equally stereotyped to both prey types. This is probably related to dietary and web structure changes in the evolution from orbweavers to theridiids, which lead to a reduction in prey capture repertoire size in this family. Among the theridiids, T. evexum has the most stereotyped predatory sequence, and this seems to be associated with the low density of threads present in its web.
\end{abstract}

Key words: Theridion evexum, predatory sequence, stereotypy, natural history, evolution.

\section{Resumo}

Para as aranhas de teia, o forrageamento inicia-se com a seleção de um local conveniente à construção da teia, sendo a seqüência predatória iniciada no momento em que a aranha entra em contato com ou recebe algum estímulo de uma presa. Aproximação, perseguição e captura da presa dão continuidade à seqüência predatória, a qual pode apresentar diferentes graus de estereotipia e plasticidade. O presente trabalho descreve a teia de Theridion evexum (Theridiidae), bem como sua seqüência predatória frente a formiga Atta sp. e a larva do besouro Tenebrio molitor. O grau de estereotipia presente no comportamento predatório de T. evexum é avaliado e comparado ao de outras três espécies de teridídeos. As seqüências predatórias dos indivíduos de T. evexum foram filmadas, transcritas ao computador e analisadas com o auxílio do programa EthoSeq, resultando em um etograma para cada presa em questão e em uma lista de rotinas comportamentais. A teia de $T$. evexum possui viscosidade em toda a sua extensão. A seleção de locais com alta umidade poderia ser adaptativa nesta espécie, pois a umidade conserva as propriedades dos fios viscosos por um maior período de tempo, reduzindo o gasto provocado pela reposição de tais fios. A captura de T. evexum frente a formiga requer um maior número de mordidas e de transportes parciais, o que sugere que a imobilização desta presa seja mais difícil que a de tenébrio. Comparando a freqüência das rotinas comportamentais obtidas para formigas e tenébrios, foi possível verificar que a seqüência predatória de $T$. evexum não apresenta diferenças de estereotipia em função das presas utilizadas. Isto provavelmente está relacionado a mudanças evolutivas na dieta e estrutura da teia dos teridídeos, as quais provocaram uma redução na diversidade de táticas de captura desta família. Com relação às outras espécies de teridídeos, T. evexum apresentou uma predação mais estereotipada, o que parece estar relacionado com a estrutura menos densa de sua teia.

Palavras-chave: Theridion evexum, seqüência predatória, estereotipia, história natural, evolução.

http://www.biotaneotropica.org.br 


\section{Introdução}

Os comportamentos pré-programados (padrões motores fixos) são chamados estereotipados e são resistentes a modificações individuais (Lorenz 1995, p. 147). Já a capacidade de lidar com diferentes tipos de situações é denominada plasticidade, e pode aumentar com a capacidade de aprendizagem do animal (Pigliucci 2001, p. 183; 185). As aranhas apresentam em seu repertório comportamental geral tanto aspectos estereotipados quanto plásticos. A construção dos fios âncora com sapatas adesivas, nas teias de Achaearanea e Latrodectus, corresponde a um comportamento estereotipado (v. Benjamin \& Zschokke 2003), assim como a seqüência de construção das ootecas nas aranhas: primeiramente elas constróem a região basal de suas ootecas, para então realizar a postura de ovos e recobrí-los com uma camada de seda (Japyassú, Macagnan \& Knysak 2003). Já no cuidado materno e nas relações sociais ocorre plasticidade. Em Coelotes terrestris Wider 1834 o cuidado materno pode aparecer mesmo em fêmeas virgens, contanto que a aranha seja exposta à presença de filhotes (Roland et al. 1996). Nesta mesma espécie, há uma plasticidade no nível de tolerância entre as aranhas, que se manifesta na variabilidade de duração do período gregário dos filhotes (Gundermann et al. 1993).

O forrageamento é um dos aspectos do comportamento das aranhas no qual se espera um alto grau de plasticidade. Ele se inicia com a seleção de um local específico e com uma quantidade de presas suficiente para suprir o requerimento energético da aranha, bem como características micro-climáticas favoráveis. Para as aranhas de teia, este local deve ainda possuir características estruturais necessárias à construção de um tipo específico de teia (Turnbull 1973). A estratégia de forrageamento geral nas aranhas de teia é a de senta-espera, a qual permite economizar energia visto que, após selecionar um local conveniente, a aranha se posiciona, geralmente no centro da armadilha, e espera até que a presa entre em contato com sua teia. Quando isto ocorre, a seqüência predatória é iniciada com a localização da presa pela aranha, sendo os estímulos emitidos pela presa fatores determinantes no comportamento da aranha. Aproximação, perseguição e captura da presa dão continuidade à seqüência predatória. O consumo da presa pode ocorrer no local de captura ou a presa pode ser transferida para o refúgio/centro da teia. Capturada a presa, muitas aranhas irão tocá-la com as pernas e/ou palpos, sendo o paladar o último teste para aceitação ou rejeição de uma presa. (Riechert \& Luczak 1982).

Características da presa afetam o comportamento das aranhas durante a seqüência predatória. Segundo Jackson et al. (1995), Diaea sp. aproxima-se mais rápido de presas que, após entrarem em contato com sua teia, continuam a se mover; esta resposta da aranha minimiza o risco da presa escapar. Japyassú \& Viera (2002) observaram em
Nephilengys cruentata Fabricius 1775 que presas maiores são mais enroladas, evitando assim que se perca um grande item alimentar. Além das características da presa, a experiência prévia das aranhas e/ou o seu estágio de desenvolvimento podem influenciar a seqüência predatória. Como exemplo temos a captura por Phidippus regius C. L. Koch 1846, que se torna mais eficaz com a experiência e se modifica com a maturação: aranhas adultas deixam de capturar formigas por estas já terem lhe causado injúrias (Edwards \& Jackson 1994). Apesar de se saber que o comportamento predatório das aranhas pode ser modificado em função de diversos fatores, poucos são os estudos que procuram quantificar o grau de estereotipia/plasticidade presentes na seqüência predatória das aranhas, ou seja, a capacidade real das aranhas de se ajustarem a diferentes contextos predatórios.

Este trabalho visa ampliar os conhecimentos sobre estereotipia e plasticidade no comportamento predatório de aranhas, bem como discutir os fatores associados a aumentos ou reduções no potencial de ajuste comportamental de uma espécie. Para isso, utilizamos uma espécie de aranha da família Theridiidae, Theridion evexum Keyserling 1884, desconhecida do ponto de vista de sua história natural. Inicialmente, descrevemos a teia de T. evexum, bem como sua seqüência predatória frente a dois tipos de presa: formiga saúva (Atta sp.; Formicidae) e larvas do besouro Tenebrio molitor (Tenebrionidae). A partir das seqüências predatórias obtidas, quantificamos o grau de estereotipia/plasticidade presente no forrageamento de T. evexum e o comparamos com o de outras três espécies de teridídeos estudadas no laboratório (Latrodectus geometricus C. L. Koch 1841; Achaearanea cinnabarina Levi 1963 e Achaearanea sp.n.).

\section{Material e Métodos}

\subsection{Theridion evexum}

A espécie de aranha utilizada no presente trabalho, Theridion evexum Keyserling 1884, pertence à família Theridiidae e já foi encontrada no sul do México, na América Central, Índia Ocidental, Colômbia, Venezuela e sudeste do Brasil (Levi 1963). O corpo das fêmeas mede entre 5 e 6 mm e o dos machos entre 3 e 3,8 mm (medidas feitas do clípeo até a parte terminal do abdome). A região dorsal do abdome de $T$. evexum apresenta uma coloração amarela com desenhos em preto e a região ventral apresenta uma mancha amarela (mais visível nas fêmeas, por estas serem maiores que os machos) circundada por faixas pretas. Diferentemente do observado em nossos exemplares, Levi (1959) descreve a região ventral do abdome das fêmeas de $T$. evexum com uma mancha branca, o que pode ser devido à perda de coloração dos exemplares depositados em coleção. As pernas de T. evexum são longas, de coloração amarelo-claro e circundadas por anéis pretos (Levi 1959; Fig. 1). 
Para a realização do presente trabalho foram utilizadas 20 fêmeas adultas de T. evexum. Apenas as fêmeas adultas foram utilizadas por não ter sido observada a construção de teias pelos machos (obs. pessoal) e pela possibilidade de aprendizado ao longo da maturação das aranhas (veja, por ex., Edwards \& Jackson 1994), o que poderia alterar as seqüências comportamentais. Exemplares testemunho de $T$. evexum foram preservados em álcool 70\% e depositados na coleção sistemática do Laboratório de Artrópodes do Instituto Butantan: IB-34.755; IB-36.000; IB-34.757; IB34.760; IB-34.758; IB-40.678; IB-40.679; IB-40.680; IB-40.681; IB-40.682; IB-40.683.

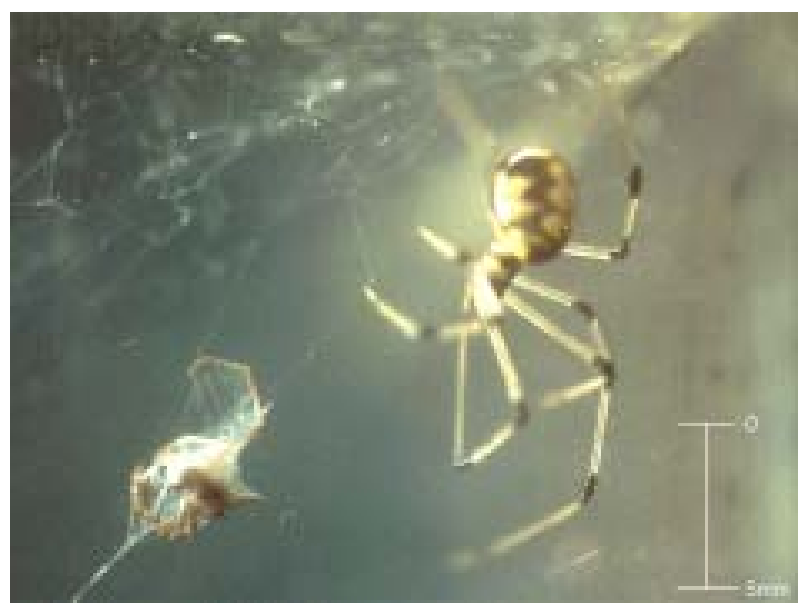

Figura 1: Theridion evexum em sua teia (construída em uma das caixas de laboratório), próxima a uma presa enrolada, limpando o tarso da perna I em suas quelíceras (foto CRM Garcia).

\subsection{Coletas e Manutenção}

Os indivíduos de $T$. evexum foram coletados no Parque Nacional do Itatiaia - RJ (entre as latitudes $22^{\circ} 19^{\prime} \mathrm{e}$ $22^{\circ} 45^{\prime} \mathrm{S}$ e longitudes $44^{\circ} 45^{\prime}$ e $44^{\circ} 50^{\prime} \mathrm{W}$ ), no dia oito de junho de 2001 e no período de três a seis de março de 2003. Das vinte fêmeas de $T$. evexum utilizadas neste trabalho, dez correspondem a filhotes que foram criados no laboratório (seis destes coletados em junho de 2001 e quatro resultantes de uma cópula realizada no laboratório) e dez correspondem a fêmeas coletadas em março de 2003.

No laboratório, as aranhas foram mantidas sob temperatura e luminosidade ambiente, acondicionadas individualmente em caixas de 21x21x21 cm, com laterais em acrílico transparente, fundo e base em poliestireno preto. Os indivíduos adultos de T. evexum foram alimentados semanalmente com um Gryllus sp. de tamanho aproximadamente igual ao corpo (cefalotórax e abdome) da aranha. Para os indivíduos de T. evexum jovens, algumas vezes foram oferecidas formigas (Atta sp.) em lugar de grilos.

\subsection{Descrição da teia e do comportamento predatório}

A teia de T. evexum foi descrita através de sua observação em campo e no laboratório, sendo medidos o comprimento dos lençóis e dos fios âncora com uma régua. Para um melhor detalhamento da estrutura de teia de $T$. evexum, foram coletadas em lâminas de vidro a base e a região média dos fios âncora, bem como fios do lençol da teia, os quais foram observados e fotografados em microscópio óptico Zeiss, modelo MC80DX.

As seqüências predatórias dos indivíduos de T. evexum foram filmadas (com uma câmera digital Canon modelo XL1). Cada indivíduo foi filmado duas vezes: uma com formiga saúva (Atta sp.), pois himenópteros são presas freqüentes na dieta de Theridiidae (Holldobler 1970, Carico 1978, MacKay 1982, Nyffeler \& Benz 1987, Nyffeler et al. 1988, Nyffeler 1999, Breene et al. 1989, 1993); outra com larva do besouro Tenebrio molitor, pois as larvas são presas raras em sua dieta (Riechert \& Luczak 1982). A escolha de uma presa freqüente e outra rara na dieta de Theridiidae visa amostrar uma grande variedade comportamental, visto que foram utilizadas presas que fornecem à aranha condições de captura bastante distintas, tendo em vista as diferenças no nível de periculosidade e na forma corpórea das presas.

Sabendo que o forrageamento pode variar de acordo com a interação da aranha com o ambiente (Pasquet et al. 1994; Japyassú \& Viera 2002), e tendo como um dos objetivos a análise da estereotipia/plasticidade da seqüência predatória da aranha frente às diferentes presas, fez-se necessária a criação de um ambiente relativamente homogêneo com relação a aspectos que influenciem o desempenho da aranha. Para isso, as filmagens das capturas foram realizadas dentro das seguintes condições: (1) num intervalo de 15 a 30 dias após a construção da teia, pois a densidade de fios aumenta com o tempo (obs. pessoal), o que pode interferir na seqüência predatória; (2) no sétimo dia após alimentação, de forma a manter o mesmo nível de saciedade para todas as aranhas; (3) sempre no período da tarde, de modo a se padronizar o momento no ciclo circadiano das aranhas; (4) com presa de tamanho aproximadamente igual ao do corpo da aranha (cefalotórax e abdome), visto que o tamanho da presa em relação à aranha altera a seqüência predatória (Japyassú \& Viera 2002).

A seqüência predatória teve início no momento em que a presa aderiu à teia da aranha e foi dividida em três fases. Fase de detecção: com início no momento em que a presa adere à teia da aranha, estendendo-se até o momento imediatamente anterior ao envolvimento da presa com goma adesiva enrolamento de captura. Fase de imobilização: inicia-se no envolvimento da presa com goma adesiva, estendendo-se até o momento em que a aranha leva a presa imobilizada para o refúgio. Fase de alimentação: do momento da chegada da aranha com a presa no refúgio até o término da seqüência 
predatória, cinco minutos após o início desta fase. Três critérios foram utilizados para determinar o encerramento da filmagem da seqüência predatória de T. evexum: (1) cinco minutos após o retorno da aranha ao refúgio, com a presa; (2) após quinze minutos de mordida longa, estando a aranha em qualquer lugar da teia; (3) após quinze minutos de pausa, estando a aranha em qualquer lugar da teia.

A seqüência predatória de T. evexum envolveu 21 categorias comportamentais. Três destas categorias não foram encontradas na literatura (repara, toque e fixação), e são descritas nos resultados. As descrições das demais categorias comportamentais (detecção, aproximação, pesca, enrolamento de captura, enrolamento, manipulação, mordida curta, mordida longa, corte de fios, fixação na presa, retorno, estiramento, recuperação, transporte, transporte com enrolamento, fixações com rotação, pausa, limpeza) são apresentadas no anexo 1 . Dado que $T$. evexum às vezes se comporta de maneira diferente da descrição original da categoria comportamental, discutimos no anexo tais alterações, quando relevantes.

\subsection{Análise das seqüências predatórias de $T$. evexum}

As filmagens foram decodificadas (transcritas) para o computador utilizando-se o programa The Observer Video Pro (Noldus et al. 2000). As seqüências de captura transcritas foram analisadas com o auxílio do programa EthoSeq (Japyassú et al. 2003), o qual elaborou uma matriz diádica de transição comportamental (matriz antecedenteconseqüente ou de primeira ordem) para cada tipo de presa. Como algumas categorias comportamentais podem ocorrer em mais de uma das fases de captura, nesta análise tais fases foram levadas em consideração. A diagonal de cada matriz foi zerada, de modo a desconsiderar uma categoria que fora sucedida por ela mesma. As matrizes foram submetidas ao teste Qui-quadrado de Brown (1974), sendo utilizadas apenas as transições significativas ao nível de $1 \%$ para a construção dos etogramas de caça frente a ambas as presas.

O programa EthoSeq permite averiguar a existência de rotinas comportamentais de primeira ordem ou de ordens superiores (sensu Alberts 1996). Para a detecção das rotinas comportamentais (seqüências longas mais freqüentes) de T. evexum foram utilizadas todas as transições comportamentais que ocorreram na captura das presas mencionadas, o que permitiu a avaliação de uma maior diversidade comportamental.

Para comparar possíveis diferenças entre a freqüência das categorias comportamentais empregadas por T. evexum na captura de formigas e tenébrios, foi utilizado o teste Wilcoxon (quando as amostras eram pareadas) ou MannWhitney. Estes testes foram utilizados tanto na comparação da freqüência de categorias comportamentais específicas (mordida longa, fixações com rotação, etc) quanto na comparação do número total de eventos (total da matriz diádica de transição - excluindo-se a diagonal principal). $\mathrm{O}$ teste de Mann-Whitney também foi empregado na comparação da freqüencia das categorias comportamentais realizadas por aranhas coletadas no campo e aquelas criadas no laboratório.

Uma análise Discriminante Canônica foi utilizada para detectar as categorias comportamentais que mais contribuem para a diferenciação entre a captura de tenébrios e formigas. As categorias comportamentais entraram na análise passo a passo, com $\mathrm{F}=0,05$ para entrada e $\mathrm{F}=0,10$ para saídas das funções discriminantes; a regra para seleção entre as categorias comportamentais disponíveis foi a minimização do Lambda de Wilks.

\subsection{Análise da Estereotipia e Plasticidade}

Para um maior detalhamento, a análise da estereotipia foi feita sob dois aspectos. Em um primeiro momento, buscou-se quantificar o quanto a seqüência predatória independe do contexto, ou seja, o quanto ela permanece invariável frente a variações no tipo de presa. Para isso utilizamos o Índice de Contextualidade (IC), o qual corresponde à porcentagem derotinas comportamentais que ocorreram de forma idêntica na captura de ambas as presas.

Em um segundo momento, buscou-se verificar o quanto as seqüências de captura são semelhantes quando as aranhas são expostas a um mesmo tipo de presa. Para isso, criamos o Índice de Generalidade(IG), o qual é calculado através da divisão do número de capturas nas quais ocorreu uma determinada rotina comportamental pelo número total de capturas amostradas. Este cálculo foi feito para tenébrios (20 capturas) eformigas (20 capturas).

Como o programa EthoSeq revela rotinas que apresentam sobreposição de díades (p.ex., enrolamento-manipulaçãomordida longa e manipulação-mordida longa-fixação possuem em comum a díade manipulação-mordida longa), realizamos um procedimento que elimina tal redundância. Neste procedimento as rotinas comportamentais que apresentaram um IG superior a $50 \%$ foram consideradas estereotipadas, e foram desmembradas em díades comportamentais; p. ex., uma rotina formada por enrolamento-manipulação-mordida longa, foi desmembrada em duas díades comportamentais: enrolamento-manipulação e manipulação-mordida longa. Cada uma destas díades comportamentais (com um IG > 50\%) foi chamada de díade estereotipada. Calculou-se então a proporção de díades estereotipadas presentes na seqüência predatória de cada indivíduo, através da divisão do total de díades estereotipadas presentes no repertório de caça deste indivíduo pelo total de díades que ele efetivamente realizou. O resultado obtido foi chamado de Grau de Estereotipia (GE), que mede a proporção de díades estereotipadas no comportamento de caça. O Grau de Estereotipia foi comparado entre os tipos de presa oferecidos através do teste de Wilcoxon (Zar 1999), tanto para a seqüência predatória inteira como para cada uma de suas fases. 
Para se testar as diferenças na captura entre quatro espécies de aranhas [estudadas no laboratório sob as mesmas condições - Latrodectus geometricus C. L. Koch 1841 (Corrêa 2001); Achaearanea cinnabarina Levi 1963 (Jotta 2002) e Achaearanea sp.n. (Caires \& Japyassú 2003), e T. evexum (presente trabalho)], no que se refere ao Grau de Estereotipia em seus repertórios de caça, utilizamos o teste Kruskal-Wallis. O teste post-hoc de Tukey foi utilizado para avaliar diferenças entre as espécies tomadas duas a duas (Zar 1999).

\section{Resultados e Discussão}

\subsection{História natural e descrição da teia}

Na coleta realizada em março de 2003, todos os indivíduos de T. evexum encontrados eram adultos, sendo que algumas fêmeas possuíam ooteca. Já na coleta realizada em junho de 2001, encontrou-se uma fêmea de T. evexum com muitos filhotes, os quais ainda estavam em estágio inicial de desenvolvimento. Através das cópulas realizadas no laboratório, foi possível verificar que as ootecas de $T$. evexum demoram de 20 a 36 dias para eclodirem. Os filhotes atingem o estágio adulto em um período que varia entre sete e oito meses. As observações acima mencionadas sugerem uma sazonalidade no ciclo reprodutivo, com fase adulta durante o verão e o outono, época em que também ocorre a reprodução da espécie; assim as ootecas eclodiriam no final do outono e o desenvolvimento dos filhotes se daria durante o inverno e primavera.

A teia de T. evexum consiste em uma estrutura tridimensional de fios. A porção de fios superiores forma um lençol irregular, onde se encontra inserido o refúgio, no qual a aranha se abriga. Do lençol partem fios verticais que se prendem ao substrato inferior e são denominados fios âncora. Na natureza, os indivíduos de T. evexum constróem sua teia entre duas folhas da vegetação. O lençol é fixado na folha superior enquanto que os fios âncoras são fixados na folha inferior. O tamanho do lençol se ajusta ao tamanho da folha à qual é fixado (observou-se uma variação de 11 a 21 cm de comprimento por 4 a $7 \mathrm{~cm}$ de largura). Compondo o refúgio, a extremidade distal da folha superior é curvada no sentido ventral, formando um pequeno “cone” no qual a aranha se abriga. No laboratório, o lençol de T. evexum variou de 8 a $20 \mathrm{~cm}$ de comprimento por 12 a $16 \mathrm{~cm}$ de largura, e a altura dos fios âncora variou entre 8 e 15 cm (no campo, a altura dos fios âncora não foi medida). O refúgio das aranhas no laboratório consistiu em uma malha de fios mais densa que a do lençol (Fig. 2). Todos os exemplares de T. evexum foram coletados em locais próximos a fluxos de água (córregos, quedas d’água) ou lagos.

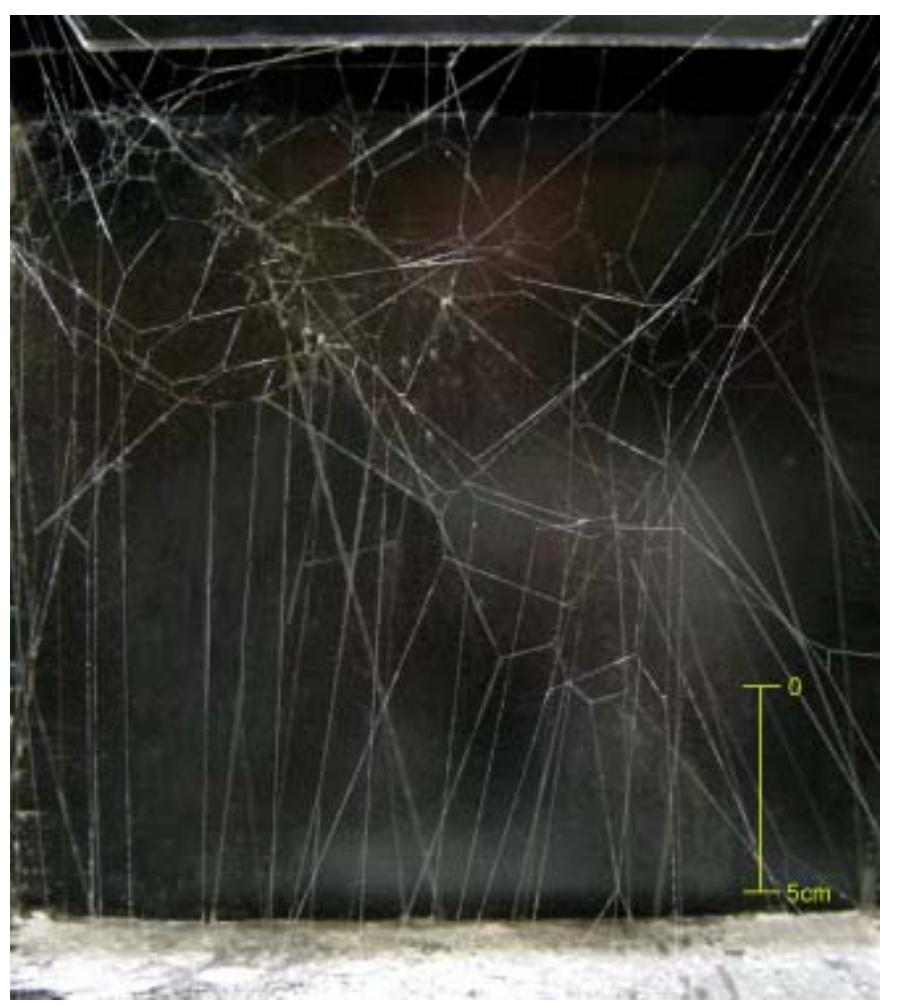

Figura 2: Estrutura de teia de T. evexum no laboratório. A aranha permanece em repouso na porção superior esquerda de sua teia (não visível na foto). A teia é composta de um lençol tridimensional difuso (na figura, na diagonal, indo da lateral superior esquerda até pouco antes da lateral inferior direita) do qual saem fios verticais (fios âncora) que se prendem ao substrato inferior. Há também fios estruturais que conectam este lençol às porções superiores da caixa (foto RP Indicatti). 
Observando a teia de T. evexum em microscópio óptico foi possível perceber que os fios âncora apresentam gotículas adesivas em toda sua extensão. O lençol de T. evexum também possui viscosidade na maioria de seus fios (Fig. 3).

Fios viscosos requerem umidade e um nível adequado de hidratação para manter suas propriedades adesivas e conservar sua elasticidade e resistência (Foelix 1996, p. 111, 116-117; Benjamin et al. 2002). A seleção de locais mais úmidos parece favorecer a conservação das propriedades dos fios viscosos da teia de T. evexum por um maior período de tempo, podendo assim ser encarada como uma estratégia comportamental para a redução dos gastos com a reposição destes fios. Tais gastos incluiriam a reposição de um nutriente considerado como um fator limitante na dieta das aranhas, a colina (para referências ver Benjamin \& Zschokke 2003), que é um componente dos fios viscosos e age como osmoprotetor, reduzindo a desidratação destes fios.

Benjamin \& Zschokke (2003) sugeriram que o alto custo da produção e manutenção de fios viscosos teria levado, ao longo da evolução, à redução da porção viscosa das teias de Theridiidae (as aranhas passaram cada vez mais a produzir teias com menor quantidade de fios viscosos). Segundo esta hipótese, T. evexum poderia ser considerada uma espécie de um grupo basal dentro da família Theridiidae pelo fato de sua teia possuir viscosidade em toda sua extensão. No entanto, Arnedo et al. (2004) mostram que aranhas do gênero Theridion são derivadas dentro da família, o que contradiz a hipótese de Benjamin \& Zschokke 2003.

\subsection{Descrição das novas categorias comportamentais}

Apresentamos abaixo as categorias comportamentais não descritas na literatura, presentes no comportamento de T. evexum.

Repara: ocorre quando a presa enrosca em um ou mais fios da teia, durante o transporte. A aranha então corta o fio abaixo e acima da presa. Enquanto segura as extremidades do fio recém cortado, a aranha fixa na presa (ou num fio próximo a ela), caso a presa não esteja ligada à aranha pelo fio guia. A aranha então fixa acima e abaixo da presa (nos fios que estava segurando), reconstituindo assim o fio original no qual a presa havia se enroscado. Esta categoria pode apresentar alguns variantes: no caso da presa ter se enroscado em mais que um fio da teia, a aranha pode cortar vários fios e, neste caso, fixações suplementares também foram observadas. Outras categorias podem permear o repara, como por exemplo, enrolamento e manipulação. Após o repara geralmente ocorre a recuperação da presa. Esta categoria não foi previamente descrita na literatura e, dentre as espécies estudadas no laboratório, repara foi observado apenas em T. evexum.

Fixação: a categoria fixação é caracterizada por fixações em fios da teia (a aranha aproxima o abdome de um fio de sua teia, toca-o com as fiandeiras, fixando um novo fio). Esta categoria pode ocorrer em todas as fases da seqüência predatória, inclusive em momentos em que a aranha não está próxima à presa. Viera (1994) descreve uma categoria denominada "fijación de hilos" que, apesar de apresentar um nome muito semelhante ao da categoria fixação, difere desta por ocorrer apenas anteriormente ao transporte da presa e não em todas as fases da captura.

Toque: a aranha simplesmente toca na presa com palpos ou pernas (I ou II). Esta categoria geralmente ocorre após aproximação e recuperação. O toque difere da manipulação (Anexo 1), a qual consiste em uma seqüência de toques alternados e consecutivos.

\subsection{Etogramas de captura de T. evexum}

Apesar do etograma da seqüência predatória de $T$. evexum frente a tenébrio apresentar muitas rotinas alternativas, a seqüência predatória que ocorreu com maior freqüência foi bastante direta. Esta seqüência inicia-se por detecções, ou seja, a aranha se desloca e tensiona os fios de sua teia a fim de localizar a presa. Essas detecções se alternam com fixações na teia até que, localizada a presa, a aranha se aproxima, toca e enrola a presa com fios que contém goma adesiva (enrolamento de captura). Em seguida a aranha inicia uma seqüência de rotinas preparatórias para o transporte da presa: enrola-a, agora com fios de seda seca (enrolamento), alternando esse enrolamento com manipulações na presa, e a libera dos fios próximos (corte de fios), para então fixar um fio na presa e iniciar o transporte direto (a aranha transporta a presa de uma só vez até o refúgio). Chegando ao refúgio, a aranha armazena a presa e volta-se à ela (fixações com rotação - 3fixR), para então tocá-la e manipulá-la. As manipulações são intercaladas com enrolamentos e mordidas longas, formando uma tríade comportamental. A captura de tenébrio é finalizada em uma mordida longa (Fig. 4).

A seqüência predatória de T. evexum frente a formiga inicia-se por detecções que se alternam com fixações na teia até que a presa seja localizada. A aranha, então, aproximase, toca a presa e a enrola com fios de seda viscosa (enrolamento de captura). Em seguida, inicia as rotinas preparatórias para o transporte da presa: enrola a presa em fios de seda seca (enrolamento), intercalando a esse enrolamento manipulações, mordidas longas e cortes de fio; a aranha então fixa um fio na presa e a transporta diretamente até o refúgio. Algumas vezes, porém, durante o transporte em direção ao refúgio, a presa fica enroscada nos fios da teia; nestes casos a aranha se distancia da presa, estirando um fio que é fixado mais acima, em sua teia. Volta-se então para a presa e a toca, retomando as atividades com ela (recuperação). Recuperada a presa a aranha volta a realizar as rotinas preparatórias para o transporte, para então novamente transportá-la. Estes transportes parciais da presa podem se repetir até que a presa se encontre no refúgio. 

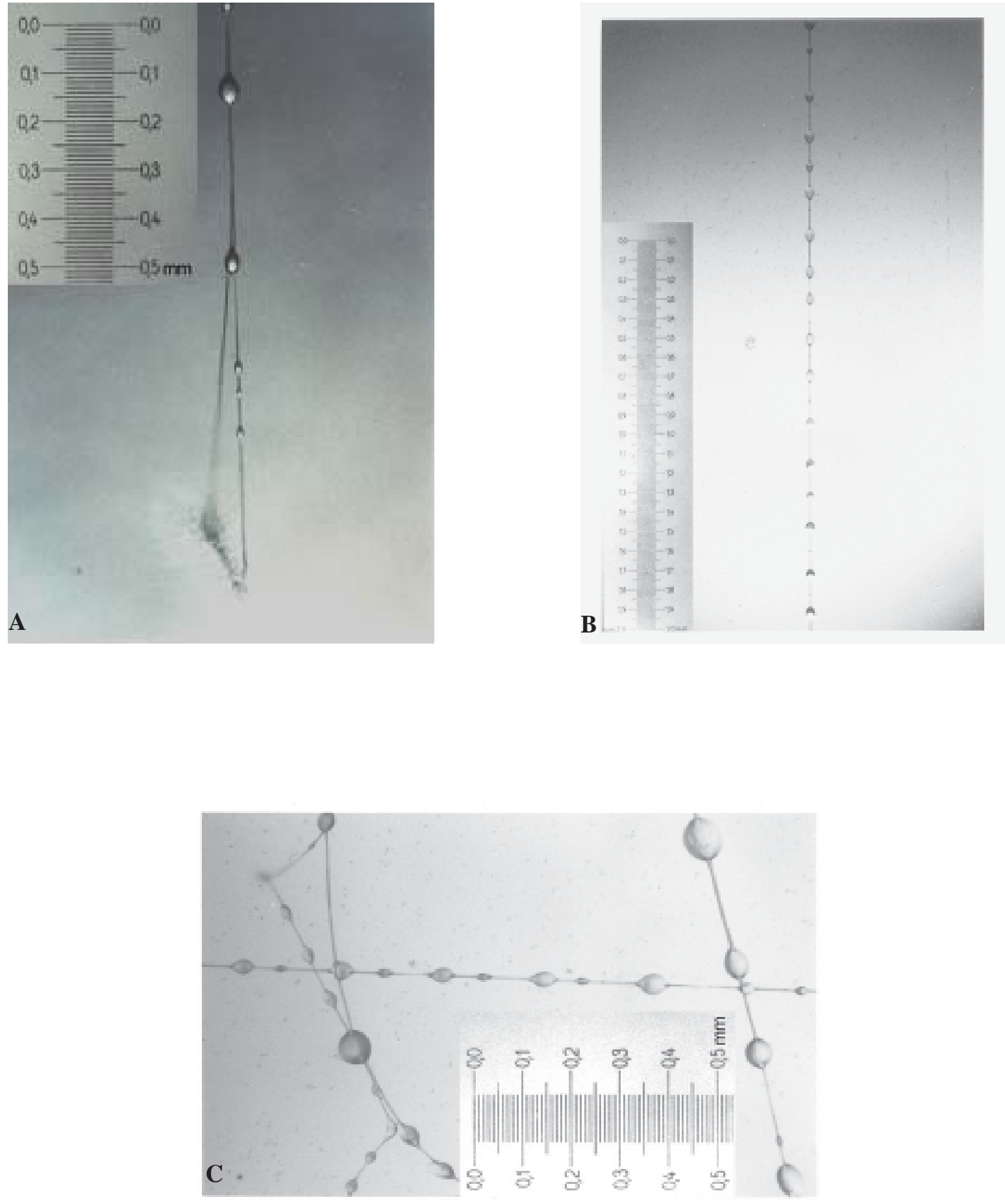

Figura 3: Micrografias dos fios da teia, mostrando a existência de gotículas adesivas em toda a extensão da teia. (a) base do fio âncora, com a placa adesiva (local onde se prende ao substrato inferior; aumento=100x); (b) extensão do fio âncora (aumento=40x); (c) fios do lençol (aumento=100x; fotos CRM Garcia).

http://www.biotaneotropica.org.br 


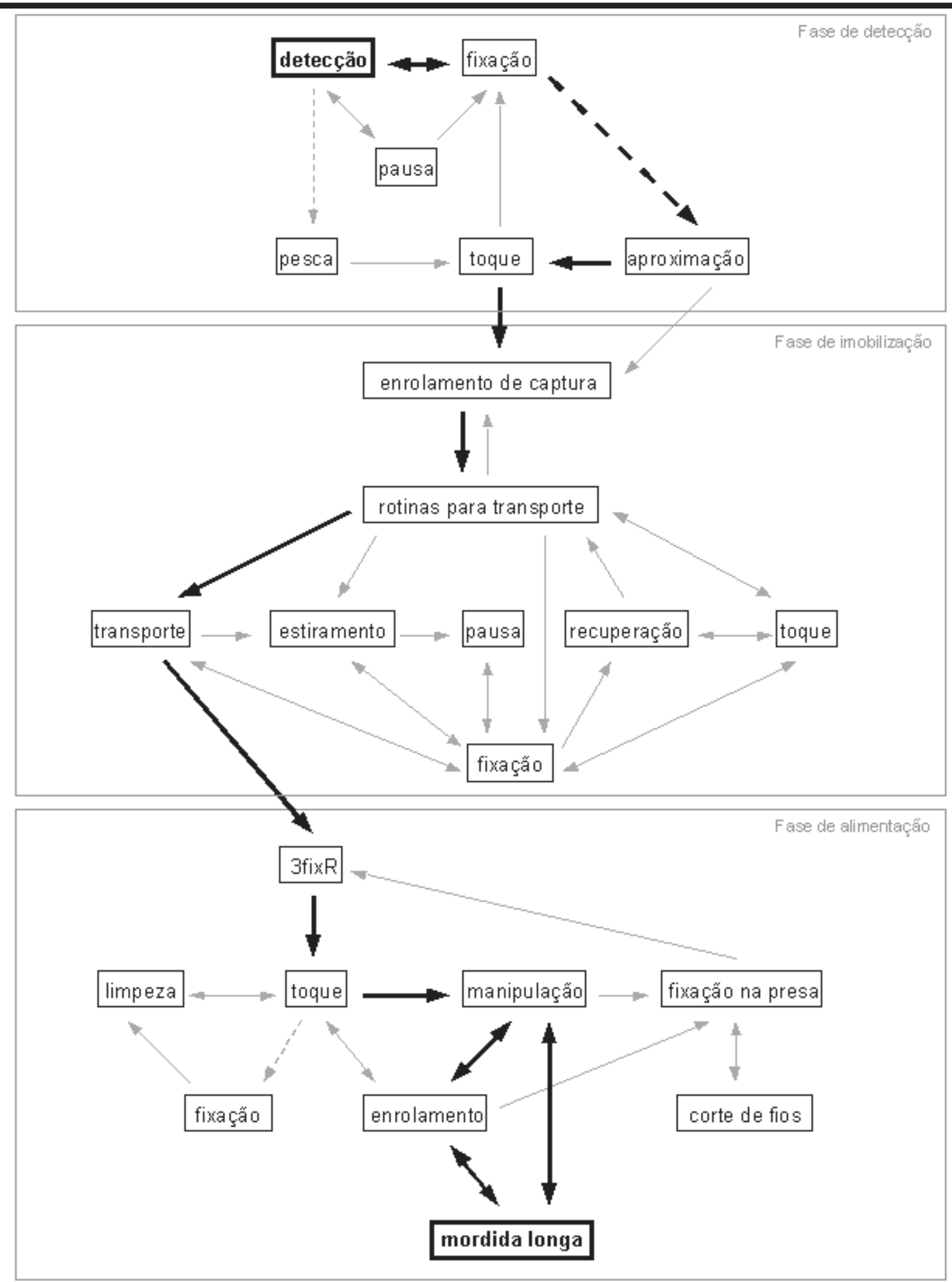

Figura 4: Etograma de caça de T. evexum frente à larva de besouro (tenébrio). Para facilitar a visualização dos etogramas, nas fases de imobilização e alimentação foram representadas apenas as transições significativas das categorias que ocorreram com uma freqüência superior à 1\% do total da matriz. Linhas contínuas: transições significativas ao nível de 1\%. Linhas pontilhadas: transições mais frequentes, não significativas ao nível de 1\%. Negrito: seqüencia predatória mais freqüente no conjunto dos dados. Categorias com o quadro em negrito indicam o início ou o fim da seqüência predatória.

http://www.biotaneotropica.org.br 
Chegando ao refúgio, a aranha armazena a presa e volta-se a ela (fixações com rotação - 3fixR), para então tocá-la e manipulá-la. As manipulações alternam-se com mordidas longas e enrolamentos com seda seca (tríade comportamental), sendo a captura de formiga finalizada por uma manipulação (Fig. 5).

\subsection{Influências do tipo de presa na captura}

Apesar das diferenças na seqüência de captura de tenébrio e formiga (ver descrições acima), não há diferenças significativas quando comparamos o número total de eventos (todas as categorias comportamentais somadas)

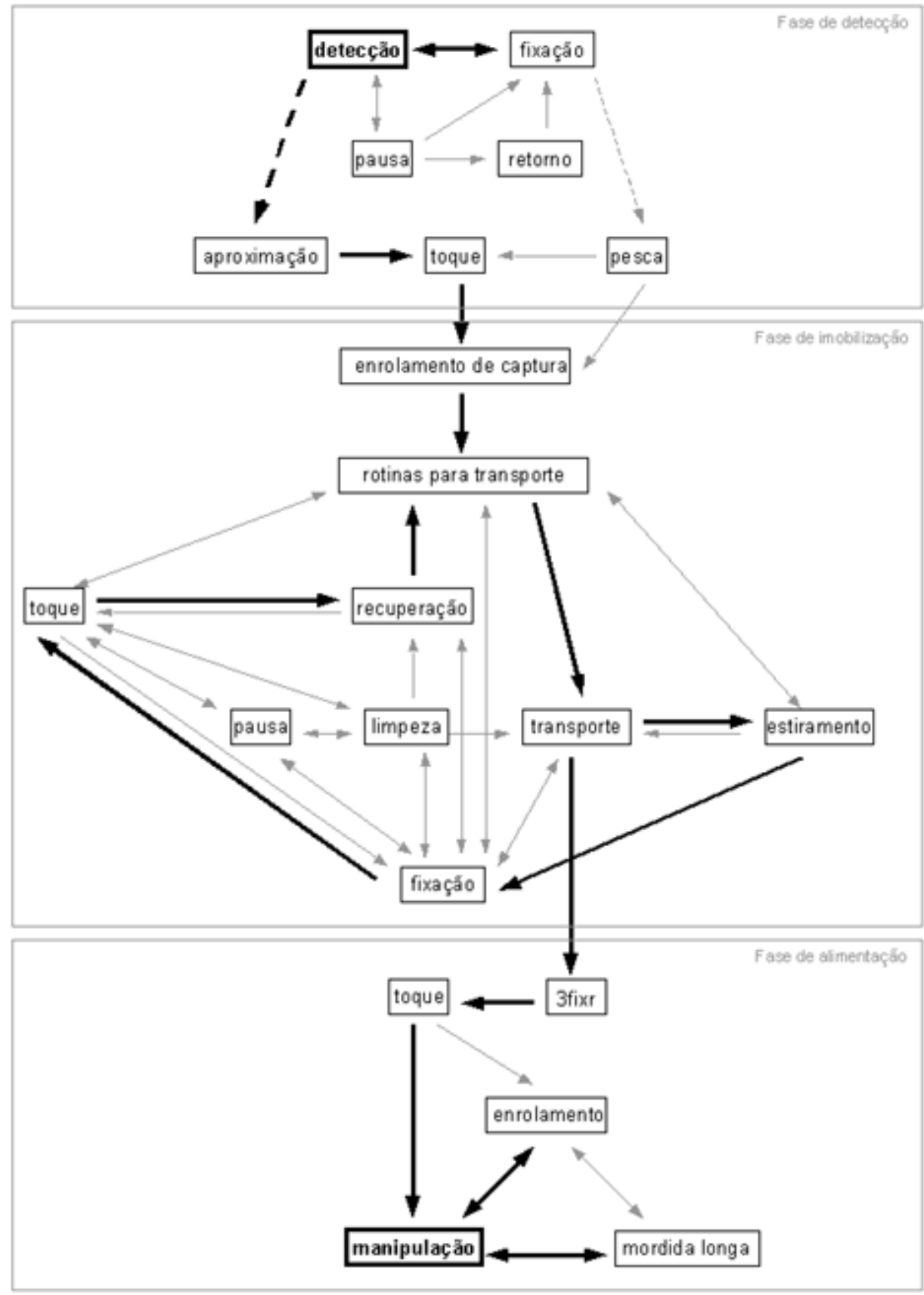

Figura 5: Etograma de caça de T. evexum frente à formiga. Para facilitar a visualização dos etogramas, nas fases de imobilização e alimentação foram representadas apenas as transiçoes significativas das categorias que ocorreram com uma freqüência superior à $1 \%$ do total de cada matriz. Linhas contínuas: transições significativas ao nível de 1\%. Linhas pontilhadas: transições mais frequentes, não significativas ao nível de 1\%. Negrito: seqüência predatória mais freqüente no conjunto dos dados. Categorias com o quadro em negrito indicam o início ou o fim da seqüência predatória.

http://www.biotaneotropica.org.br 
com cada tipo de presa ( $N=40 ; Z=-0,672 ; P=0,501)$. Analisando-se a contribuição da freqüência de cada uma das 21 categorias comportamentais (análise Discriminante Canônica), percebemos que mordida longa e fixações com rotação são as categorias que mais diferem na captura dos dois tipos de presa $\left(\mathrm{N}=40 ; \chi^{2}=14,593 ; \mathrm{P}=0,001\right)$. Mordida longa é a categoria que mais difere entre os grupos, e esta diferença é mais marcada na fase de imobilização (ver abaixo). Analisando-se as diferenças e semelhanças na captura em cada uma de suas fases (detecção, imobilização e alimentação), notamos que de um modo geral é a fase de imobilização a que apresenta mais diferenças.

A similaridade das fases de detecção da seqüência predatória de T. evexum frente a formiga e a tenébrio poderia ser justificada por, nesta fase, a aranha utilizar um pequeno número de categorias comportamentais, que em conjunto serviriam apenas para localizar o fio âncora onde a presa está aderida. Esta pequena diversidade de categorias empregadas na fase de detecção também foi observada em outras aranhas, tais como: Metepeira seditiosa Keyserling 1893 (Araneidae; Viera 1994), Pholcus phalangioides Fuesslin 1775 (Pholcidae; Jackson \& Brassington 1987), Nephilengys cruentata (Tetragnathidae; Japyassú \& Viera 2002) e Diaea sp. (Thomisidae; Jackson et al. 1995). Esta semelhança muito provavelmente é fruto de uma convergência evolutiva, haja vista a distância filogenética entre as famílias que apresentaram pequeno repertório comportamental nesta fase da captura.
Para imobilizar uma presa, além do enrolamento as aranhas utilizam mordidas, através das quais inoculam uma toxina na presa, causando sua paralisação (Turnbull 1973). Durante a fase de imobilização de formigas houve uma maior freqüência de mordidas longas que durante a fase de imobilização de tenébrios ( $\mathrm{P}=0,019 ; \mathrm{N}=20$; $\mathrm{Z}=-2,339$; Fig. 6), o que sugere que esta presa possua certa resistência à toxina da aranha. Uma outra possibilidade seria a difusão mais lenta do veneno na formiga: suas divisões corpóreas mais definidas poderiam dificultar a difusão da toxina entre os segmentos. Carico (1978) relata que ao alimentar-se de formiga, Euryopis funebris (Hentz, 1850; Theridiidae) a morde em regiões membranosas, como articulação das pernas, base das antenas ou o cérvix. T. evexum parece procurar tais regiões para a aplicação de suas mordidas em formigas, o que não acontece com tenébrios. Ao ter que morder em várias articulações, a freqüência de mordida aumenta. Os transportes parciais são mais freqüentes na captura de formigas porque, ao continuar a se movimentar mesmo após enrolada, esta presa se enrosca mais freqüentemente nos fios da teia.

As fases de alimentação de T. evexum foram muito semelhantes para ambas as presas. Isto pode ser justificado por nesta fase as presas já estarem relativamente contidas, cabendo à aranha armazenar a presa no refúgio e iniciar a tríade comportamental manipula-enrola-morde, reforçando ainda mais a imobilização da presa antes de se alimentar. É provável que nesta etapa da captura as mordidas passem a ter como função a ingestão de alimento.

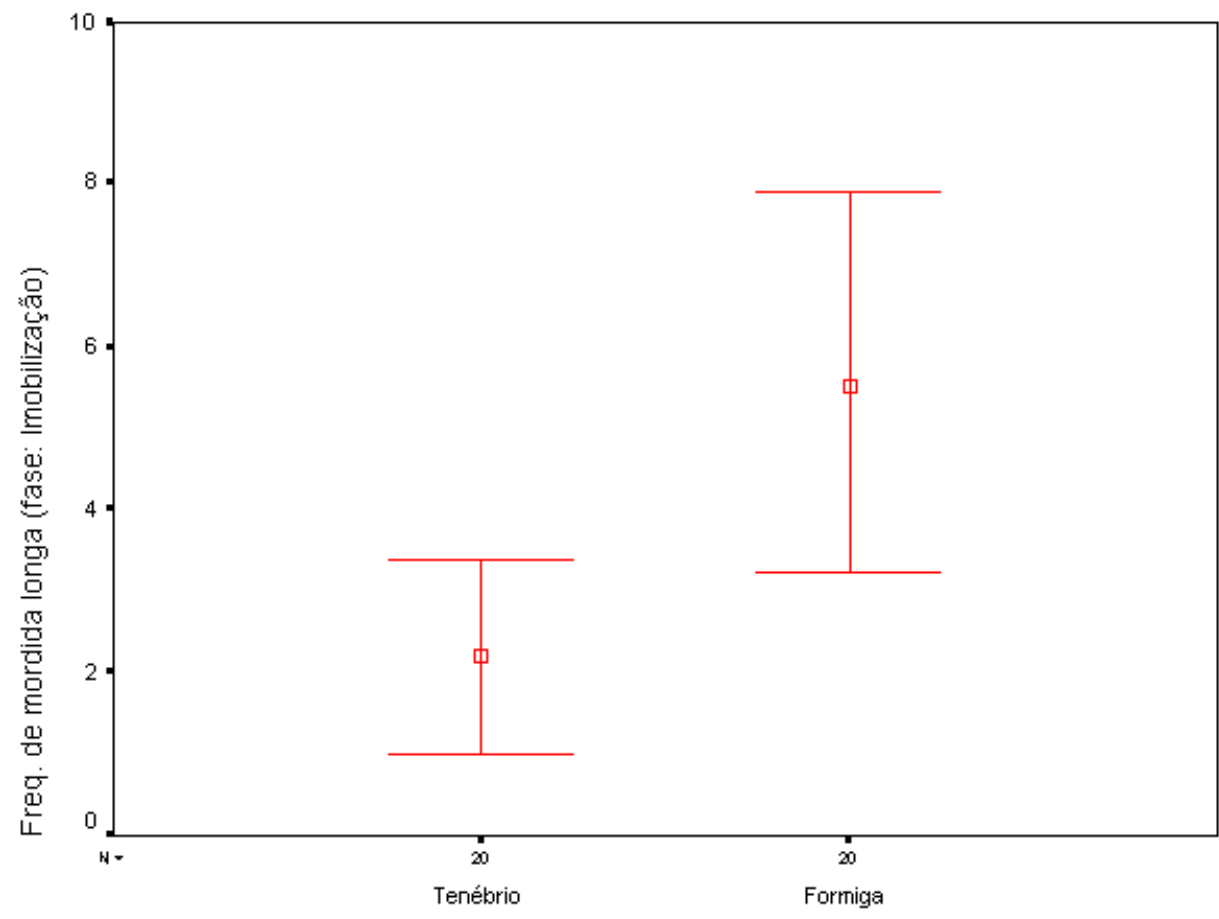

Tipo de presa

Figura 6: Freqüência de mordidas longas na fase de imobilização da seqüência predatória de T. evexum frente a tenébrio e a formiga (valores: média +/- 2 SE). 


\subsection{Estereotipia e plasticidade na seqüência predatória}

\subsubsection{Grau de Estereotipia}

A seqüência predatória de T. evexum não apresentou diferenças de estereotipia em função dos tipos de presa utilizados, tanto no que se refere à seqüência predatória como um todo $(\mathrm{P}=0,794 ; \mathrm{N}=20 ; \mathrm{Z}=-0,261)$ quanto para cada uma de suas fases (fase de detecção: $P=0,570 ; N=20 ; Z=-$ 0,568; fase de imobilização: $P=0,911 ; N=20 ; Z=-0,112$; fase de alimentação: $\mathrm{P}=0,1 ; \mathrm{N}=20 ; \mathrm{Z}=-1,643$ ). Isto provavelmente está relacionado a mudanças evolutivas na dieta e estrutura da teia dos teridídeos, que envolvem alterações em vários aspectos do comportamento destas aranhas. Japyassú \& Caires (em prep.) mostram que as espécies da família Theridiidae apresentam uma pequena diversidade de táticas de capturas (no máximo três) quando comparadas às outras famílias (araneídeos, por exemplo, podem realizar até seis táticas de captura). Esta reduzida diversidade de táticas de caça entre os teridídeos parece relacionada à estrutura de sua teia, que captura preferencialmente presas cursoriais muitas das quais são presas potencialmente perigosas, como as formigas (Holldobler 1970, Carico 1978, MacKay 1982, Nyffeler \& Benz 1987, Nyffeler et al. 1988, Nyffeler 1999, Breene et al. 1989, 1993). A grande freqüência de formigas na dieta dos teridídeos poderia ter exercido uma pressão seletiva sobre seu comportamento predatório, fazendo com que as aranhas reajam a qualquer tipo de presa como se esta fosse uma presa potencialmente perigosa. Assim, esta seleção de táticas de captura mais voltadas a presas potencialmente perigosas teria levado a uma diminuição no repertório de captura dos teridídeos que, dessa forma, teria se tornado mais estereotipado. Esta redução na diversidade de táticas de capturas dos teridídeos não implica que as rotinas realizadas por $T$. evexum para capturar tenébrios e formigas sejam iguais, mas sim que as diferentes rotinas empregadas na captura destas presas sejam realizadas com o mesmo grau de estereotipia.

\subsection{2 Índice de Contextualidade}

Do total de 835 rotinas obtidas, 395 ocorreram na captura de ambos os tipos de presa, apresentando portanto $\mathrm{IC}=47,3 \%$. Isto nos mostra que, apesar de seu elevado grau de estereotipia, T. evexum possui a capacidade de se ajustar ao contexto predatório, o que fica evidente no fato de que nenhuma presa foi descartada ou provocou algum tipo de injúria às aranhas. Porém, esta capacidade de ajuste ao contexto de $T$. evexum ainda é menor que a de espécies pertencentes a famílias de aranhas orbitelas. Como exemplo temos N. cruentata e Nephila clavipes (Linnaeus 1767; Tetragnathidae) que apresentam IC=19,47\% (Japyassú \& Viera 2002) e 34,94\% (Oliveira \& Japyassú, 2004), respectivamente, e Metazygia rogenhoferi Keyserling 1878
(Araneidae) que apresenta IC=35,1\% (Garcia et al. em prep.). É de se esperar sempre algum tipo de plasticidade comportamental no repertório de caça das aranhas, se levarmos em conta as condições de escassez de alimento que moldaram a evolução do grupo como um todo (v. revisão em Wise 1993, pp.19-40); tal situação favoreceria um predador generalista e oportunista, o qual deveria necessariamente apresentar táticas de captura ajustáveis aos diferentes tipos de presa disponíveis.

\subsection{Outras influências na captura}

As seqüências predatórias de aranhas coletadas adultas na natureza ( $\mathrm{N}=10$; grupo Campo) apresentaram maior freqüência de categorias comportamentais $(\mathrm{P}=0,002$; $\mathrm{N}=40 ; \mathrm{U}=88,0)$ que aquelas que foram criadas no laboratório ( $N=10$; grupo Lab). Teoricamente, tal diferença pode ter duas explicações alternativas. Ela pode ser devida a diferenças no grau de parentesco ou na experiência prévia entre os componentes dos dois grupos.

Os indivíduos do grupo Lab são todos de uma mesma linhagem (seis são filhos de uma mesma fêmea e quatro são resultantes do cruzamento entre estes “irmãos”), o que é improvável para as aranhas do grupo Campo, que foram coletadas em áreas distantes até 300m uma da outra. Com relação à experiência prévia, os indivíduos do grupo Lab foram expostos a poucos tipos de presa (Gryllus sp. e Atta sp.) durante seu desenvolvimento, o que certamente não é o caso dos indivíduos na natureza, visto que teridídeos capturam, na natureza, não apenas insetos de várias ordens diferentes, mas também outros aracnídeos (Riechert \& Luczak, 1982, para Achaearanea e Nyffeller 1999 para Achaearanea, Latrodectus e Theridion).

Caso a diferença na captura seja devida a fatores genéticos (grau de parentesco), é de se esperar que a maior freqüência de categorias comportamentais observada no grupo Campo ocorra tanto na captura de tenébrios quanto na captura de formigas; ou seja, é esperado que as predisposições genéticas afetem o forrageamento como um todo. Por outro lado, se a diferença na captura for devida a diferenças na experiência prévia, é de se esperar que na captura de tenébrio (presas com a qual ambos os grupos não têm experiência prévia - larvas são muito raras na dieta de teridídeos - Riechert \& Luczak 1982) não ocorra diferença na freqüência de categorias entre os grupos. Já na captura de formigas, é esperada uma diferença entre os grupos, dado que o grupo Lab tem experiência apenas com Atta sp., enquanto que as aranhas na natureza se confrontam com várias espécies de formiga.

Analisando a figura 7, vemos que não há diferenças entre os grupos Campo e Lab no que se refere à freqüência de categorias comportamentais durante a captura de tenébrios ( $\mathrm{P}=0,529 ; \mathrm{N}=20 ; \mathrm{U}=41,5)$, e que tal diferença ocorre na captura de formigas $(P=0,0001 ; N=20 ; U=6,0)$. Estes 
resultados corroboram a hipótese de que a experiência prévia com uma variedade maior de táxons na natureza é responsável pelas diferenças comportamentais entre os grupos Campo e Lab. Sabendo que a experiência prévia com presas afeta o comportamento das aranhas (Edwards \& Jackson 1994; Punzo 2002), os indivíduos do grupo Campo, por terem tido contato com várias espécies de formigas, realizariam algumas categorias com maior freqüência visando evitar o risco de injúrias provocadas tanto pelas mandíbulas das formigas quanto pelo ácido fórmico que algumas espécies expelem. Categorias como enrolamento e mordida longa foram utilizadas com maior freqüência pelo grupo Campo, e estão associadas a uma maior imobilização da presa (Turnbull 1973). Já o grupo Lab teve contato apenas com formigas Atta sp., as quais não possuem ácido fórmico (Brandão, comunicação pessoal), representando, portanto, um menor risco de injúrias às aranhas, que conseqüentemente apresentaram uma menor freqüência de categorias na captura desta presa.

\subsection{Estereotipia predatória em Theridiidae}

O Grau de Estereotipia (GE) varia entre as espécies estudadas no laboratório (T. evexum, L. geometricus, A. cinnabarina e Achaearanea sp.n.; $\mathrm{P}<0,001 ; \mathrm{N}=160$; $\left.\chi^{2}=52,495\right)$. T. evexum foi a espécie que apresentou a seqüência predatória mais estereotipada (Fig. 8), diferindo significativamente de Achaearanea sp.n. e de L. geometricus $(\mathrm{P}<0,05)$ e marginalmente de $A$. cinnabarina $(\mathrm{P}=0,059$, tabela 1). Este fato pode ser explicado pela estrutura simplificada da teia desta espécie, que é menos densa que a de $L$. geometricus, A. cinnabarina e Achaearanea sp.n. (compare figuras 2 e 9), o que facilitaria tanto a fase de detecção da presa quanto seu transporte até o refúgio (menor chance da presa enroscar em fios da teia durante o transporte).

Latrodectus geometricus apresenta estereotipia semelhante à de $A$. cinnabarina, o que pode ser explicado também pela estrutura de suas teias, semelhantes tanto no tamanho quanto na densidade de fios. Já Achaearanea sp.n. é a espécie que apresenta o maior grau de plasticidade

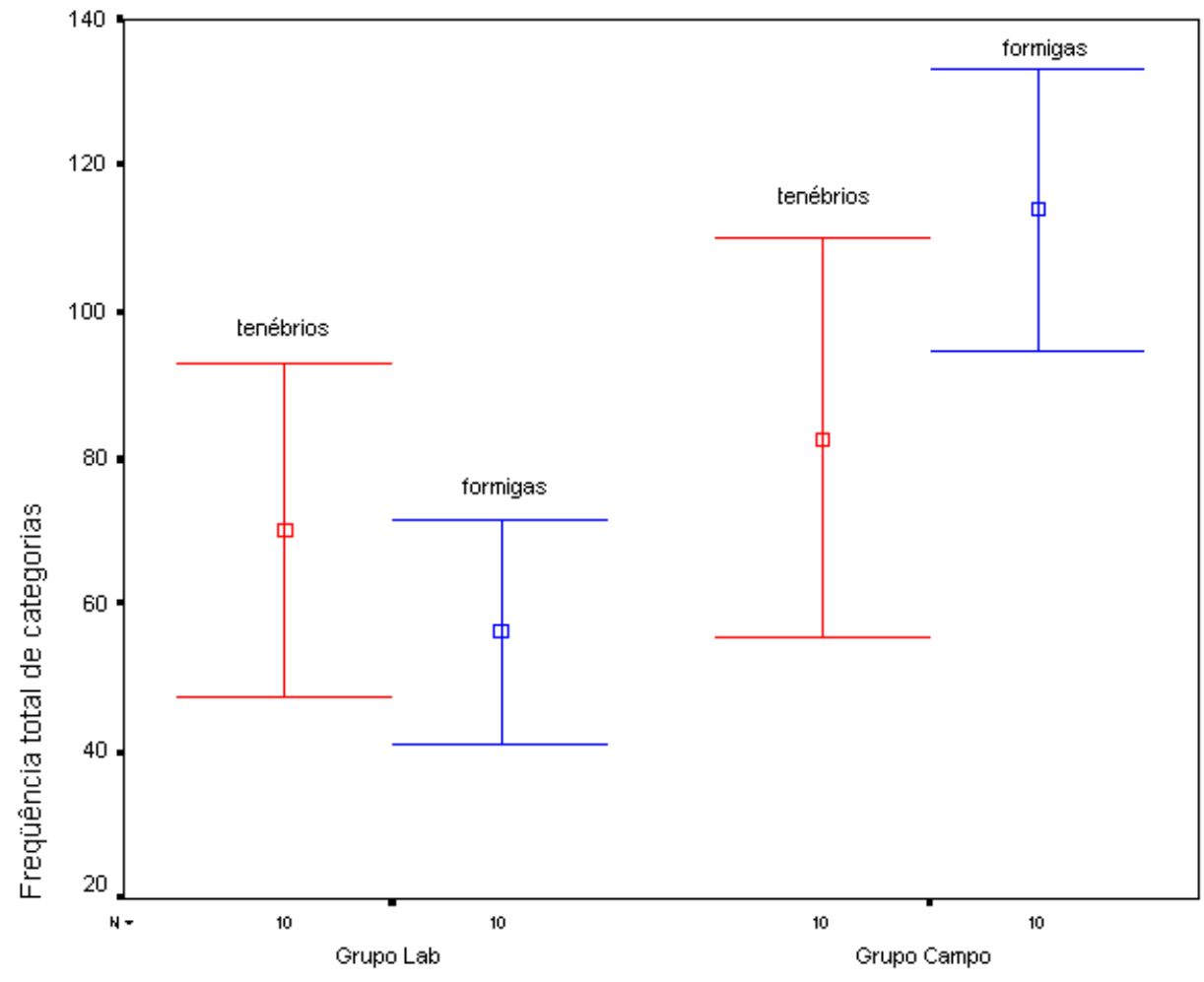

Figura 7: Freqüência total de categorias comportamentais realizadas por aranhas dos grupos Campo e Lab, com as presas tenébrio e formiga (valores: média +/- 2 SE). 
predatória, diferindo das espécies restantes. A maior plasticidade na captura de Achaearanea sp.n. pode ser explicada pelo tamanho diminuto desta espécie com relação ao das outras três espécies em questão. Como conseqüência deste fato, presas maiores que a aranha terminaram sendo utilizadas algumas vezes e, como observado por Japyassú \& Viera (2002), alterações no tamanho da presa implicam em modificações do comportamento predatório. Estes resultados sugerem que a complexidade da armadilha pode ser um dos fatores que afetam o grau de estereotipia no comportamento predatório.

\section{Conclusões}

T. evexum só foi encontrada em microlocais com alta umidade. Tal associação poderia levar a uma redução na freqüência de renovação dos fios viscosos de sua teia, já que essa umidade é importante para manter a adesividade e a elasticidade dos fios.

A análise comparativa das teias de teridídeos sugere que a densidade das teias afeta o grau de estereotipia predatória; espécies com teias pouco densas, como T. evexum, apresentam seqüências predatórias mais estereotipadas que espécies com teias mais densas. A menor densidade de fios facilita tanto a localização da presa na armadilha como o transporte da presa até o refúgio (a presa irá se enroscar menos nos fios da teia durante o transporte), resultando conseqüentemente em uma maior estereotipia comportamental.

Apesar dos teridídeos apresentarem um repertório de caça menos diversificado e, portanto, mais estereotipado que o das aranhas orbitelas, notamos que os indivíduos desta família ainda são capazes de se ajustarem ao contexto predatório em que estão inseridos. A capacidade de se ajustar a diferentes contextos predatórios representa uma grande vantagem para os indivíduos de $T$. evexum, pois permite que esta espécie se alimente de qualquer presa que caia em sua teia. Como um exemplo deste ajuste ao contexto, vimos que T. evexum aplica mordidas com maior freqüência para imobilizar formigas que para imobilizar tenébrios.

\section{Agradecimentos}

Este trabalho não teria sido possível sem a colaboração de Cátia Regina Macagnan, Ana Maria Macedo e Igor Cizauskas. Rodrigo Caires e Eduardo Jotta forneceram gentilmente ilustrações e acesso a dados não publicados. Dois pareceristas anônimos contribuiram significativamente para a melhoria do manuscrito original. Financiamento: Fapesp (processos 99/04442-9; 02/08900-6 e 99/05446-8) e Fundap.

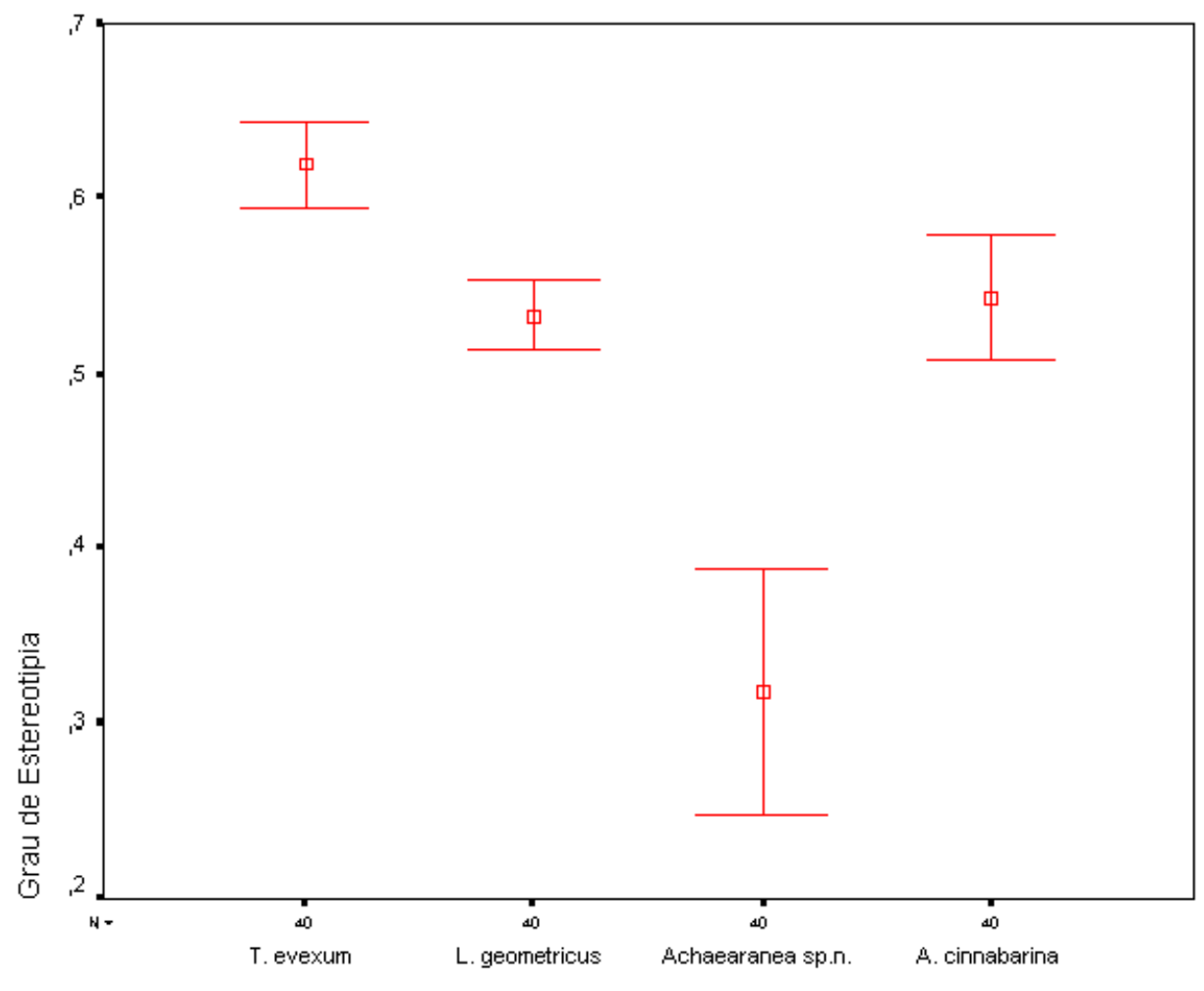

Figura 8: Comparação dos GEs (Graus de Estereotipia) das seqüências predatórias de A. cinnabarina, T. evexum, L. geometricus e Achaearanea sp.n. (valores: média +/- 2 SE). 

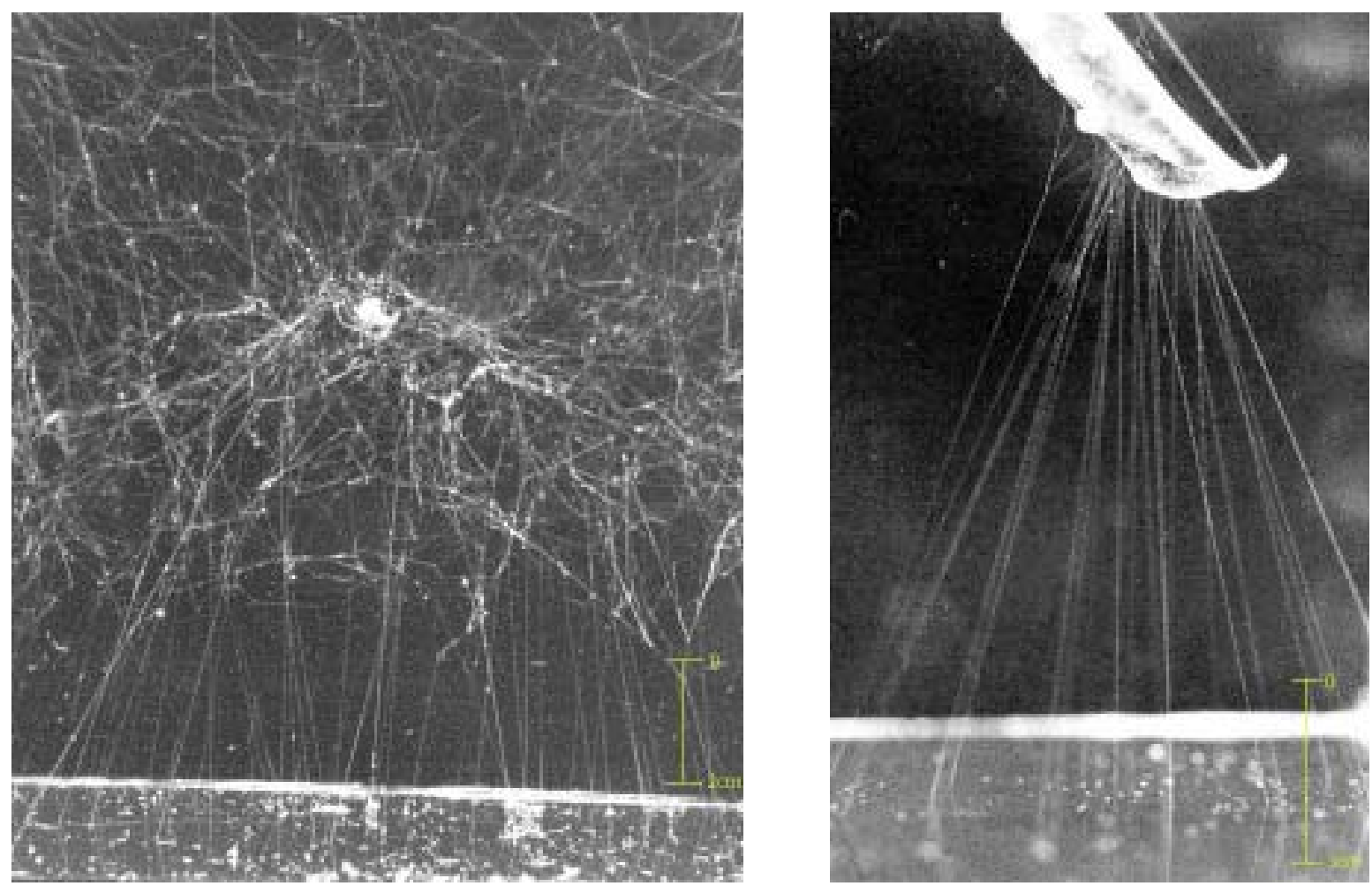

Figura 9: Teias de outros teridídeos. (a) Achaearanea cinnabarina (foto EG Jotta); (b) Achaearanea sp.n. (foto RA Caires).

\begin{tabular}{|l|l|c|}
\hline \multicolumn{1}{|c|}{ Espécie de aranha 1 } & Espécie de aranha 2 & $\begin{array}{c}\text { Grau de } \\
\text { significância (P) }\end{array}$ \\
\hline T. evexum & A. cinnabarina & 0,059 \\
& L. geometricus & 0,024 \\
& Achaearanea sp.n. & $<0,001$ \\
\hline L. geometricus & A. cinnabarina & 0,989 \\
& T. evexum & 0,024 \\
& Achaearanea sp.n. & $<0,001$ \\
\hline A. cinnabarina & T. evexum & 0,059 \\
& L. geometricus & 0,989 \\
& Achaearanea sp.n. & $<0,001$ \\
\hline Achaearanea sp.n. & A. cinnabarina & $<0,001$ \\
& T. evexum & $<0,001$ \\
& L. geometricus & $<0,001$ \\
\hline
\end{tabular}

Tabela 1. Comparação entre os GEs (Graus de Estereotipia) das espécies analisadas, tomadas duas a duas (teste post-hoc de Tukey).

http://www.biotaneotropica.org.br 


\section{Referências Bibliográficas}

ALBERTS, C. C. 1996. O comportamento de autolimpeza do gato doméstico (Felis catus) e uma proposta para usá-lo como caractere filogenético. (Tese de Doutorado. Instituto de Psicologia. Universidade de São Paulo - SP)

ARNEDO, M. A., CODDINGTON, J., AGNARSSON, I. \& GILLESPIE, R. G. 2004. From a combto a tree: phylogenetic relationships of the comb-footed spiders (Araneae, Theridiidae) inferred from nuclear and mitochondrial genes. Mol. Phylogenet. Evol., 31: 225-245.

BENJAMIN, S. P., DÜGGELIN, M. \& ZSCHOKKE, S. 2002. Fine structure of sheet-webs of Linyphia triangularis (Clerck) and Microlyniphia pusilla (Sundevall), with remarks on the presence of viscid silk. Acta Zool., Stockh., 83: 49-59, jan.

BENJAMIN, S. P. \& ZSCHOKKE, S. 2003. Webs of theridiid spiders: construction, structure and evolution. Biol. J. Linn. Soc., 78: 293-305.

BREENE, R. G., STERLING, W. L. \& DEAN, D. A. 1989. Spider and ant predators of the cotton fleahopper on wooly croton. Southwest. Entomol. 13: 177-183.

BREENE, R.G., MEAGHER, R.L. Jr., \& DEAN, D.A. 1993. Spiders (Araneae) and ants (Hymenoptera: Formicidae) in Texas sugarcane fields. Florida Entomol. 76: 645-650.

BROWN, M. B. 1974. Identification of the sources of significance in two-way contingency tables. ApII. Statist., 23 (3): 405.

CAIRES, R. A. \& JAPYASSÚ, H. F. 2003. Predatory plasticity in a new spider species: an expression of web architecture? Rev. Etol. Suplemento, 5: 149.

CARICO, J. E. 1978. Predatory behavior in Euryopis funebris (Hentz) (Araneae: Theridiidae) and the evolutionary significance of web reduction. Symp. zool. Soc. Lond., 42: 51-58.

CODDINGTON, J. A. 1986. The monophyletic origin of the orb web. In: Shear, W. A. (eds.). Spiders: webs, behavior, and evolution. Stanford, Califórnia: Stanford University Press. p. 319-363.

CORRÊA, J. P. 2001. Forrageamento em Latrodectus geometricus (Araneae: Theridiidae): plasticidade e aspectos comparativos. 47p. (Monografia de Bacharelado. Universidade de Santo Amaro - SP)

EDWARDS, G. B. \& JACKSON, R. R. 1994. The role of experience in the development of predatory behaviour in Phidippus regius, a jumping spider (Araneae, Salticidae) from Florida. $N$. Z. J. Zool., 21: 269-277.

FOELIX, R. F. 1996. Biology of spiders. New York: Oxford University Press. p.111; 116-117.

GUNDERMANN, J. L.; HOREL, A. \& KRAFFT, B. 1993. Experimental manipulations of social tendencies in the subsocial spider Coelotes terrestris. Ins. Soc., 40: 219-229.

HOLLDOBLER, B. 1970. Steatoda fulva (Theridiidae), a spider that feeds on harvester ants. Psyche 77: 202-208.

JACKSON, R. R. \& BRASSINGTON, R. J. 1987. The biology of Pholcus phalangioides (Araneae, Pholcidae): predatory versatility, araneophagy and agressive mimicry. J. Zool., London, 221: 227-238.
JACKSON, R. R.; TAYLOR, P. W.; MCGILL, A. S. \& POLLARD, S. D. 1995. The web and prey-capture behaviour of Diaea sp., a crab spider (Thomisidae) from New Zealand. Rec. West. Aust. Mus. Supplement, 52: 33-37.

JAPYASSÚ, H.F., ALBERTS, C.C., IZAR, P. \& SATO, T. 2003. EthoSeq: a tool for phylogenetic analysis and data mining on behavioural sequences. Rev. Etol. Suplemento, 5: 104.

JAPYASSÚ, H. F. \& MACAGNAN, C. R. em preparação. On a new predatory tactic among pholcid spiders (Araneae, Pholcidae): the use of gumfoots and theriid wrap attack behaviour. J. Zool., London.

JAPYASSÚ, H. F., MACAGNAN, C. R. \& KNYSAK, I. 2003. Eggsac recognition in Loxosceles gaucho (Araneae, Sicariidae) and the evolution of maternal care in spiders. $J$. Arachnol., 31: 90-104.

JAPYASSÚ, H. F. \& VIERA, C. 2002. Predatory plasticity in Nephilengys cruentata (Araneae: Tetragnathidae): relevance for phylogeny reconstruction. Behaviour, 139: 529-544.

JOTTA, E.G. 2002. Análise do comportamento de captura de Achaearanea cinnabarina (Araneae: Theridiidae). 63p. (Monografia de Bacharelado. Universidade Presbiteriana Mackenzie - SP)

LEVI, H. W. 1959. The spider genera Achaearanea, Theridion and Sphyrotinus from Mexico, Central America and the West Indies (Araneae, Theridiidae). Bull. Mus. Comp. Zool., Cambridge, Mass., 121 (3): 57-163.

LEVI, H. W. 1963. American spiders of the genus Theridion (Araneae: Theridiidae). Bull. Mus. Comp. Zool., Cambridge, Mass., 129 (10): 481-589.

LORENZ, K. 1995. Os fundamentos da etologia. São Paulo: Editora da Universidade Estadual Paulista. p. 147.

MACKAY, W.P. 1982. The effect of predation of western widow spiders (Araneae: Theridiidae) on harvest ants (Hymenoptera: Formicidae). Oecologia (Berl) 53: 406-411.

NOLDUS, L.P.J.J., TRIENES, R.J.H., HENDRIKSEN, A.H.M., JANSEN, H. \& JANSEN, R.G. 2000. The Observer Video-Pro: new software for the collection, management, and presentation of time-structured data from videotapes and digital media files. Behav. Res. meth. Ins. \& C., 32, 197-206.

NYFFELER, M. 1999. Prey selection of spiders in the field. $J$. Arachnol., 27: 317-324.

NYFFELER, M. \& BENZ, G. 1987. Spiders in natural pest control: a review. J. Appl. Entomol., 103: 321-339.

NYFFELER, M., DEAN, D. A. \& STERLING, W. L. 1988. The southern black widow spider, Latrodectus mactans (Araneae, Theridiidae), as a predator of the red imported fire ant, Solenopsis invicta (Hymenoptera, Formicidae), in Texas cotton fields. J. Appl. Entomol., 106: 52-57.

OLIVEIRA, A. C. C. \& JAPYASSÚ, H. F. 2004. Comportamento predatório de Nephila clavipes Linnaeus 1767 (Tetragnathidae) e evolução de estratégias de ataque nas aranhas de teia orbicular. 26p. (Monografia de Bacharelado. Universidade de Franca - SP)

PASQUET, A.; RIDWAN, A. \& RAYMOND, L. 1994. Presence of potential prey affects web-building in an orb-weaving spider Zygiella x-notata. Anim. Behav., 47: 477-480. 
PIGLIUCCI, M. 2001. Phenotypic plasticity: beyond nature and nurture. Maryland: The Johns Hopkins University Press. p. 183; 185.

PUNZO, P. 2002. Food imprinting and subsequent prey preference in the lynx spider, Oxyopes salticus (Araneae: Oxyopidae). Behav. Processes, 58: 177-181.

RIECHERT, S. E. \& LUCZAK, J. 1982. Spider foraging: behavioral responses to prey. In: Witt \& Rovner (eds). Spider communication: mechanisms and ecological significance. New Jersey: Princeton University Press. p. 353-385.

ROBINSON, M. H. 1969. Predatory behavior of Argiope argentata (Fabricius). Am. Zool., 9: 161-173.

ROBINSON, M. H. \& OLAZARRI, J. 1971. Units of behavior and complex sequences in the predatory behavior of Argiope argentata (Fabricius): (Araneae: Araneidae). Smithson. Contrib. Zool., 65: 1-36.

ROLAND, C.; GUNDERMANN, J. L. \& HOREL, A. 1996. Maternal state induction in female spiders by the young. Behaviour, 133: 1125-1131.

TURNBULL, A. L. 1973. Ecology of the true spiders (Araneomorphae). Ann. Rev. Entomol., 18: 305-348.

VIERA, C. 1986. Comportamiento de captura de Metepeira sp. A (Araneae, Araneidae) sobre Acromyrmex sp. (Hymenoptera, Formicidae) en condiciones experimentales. Aracnologia, Montevideo, 6: 1-8.

VIERA, C. 1994. Análisis del comportamiento de predator de Metepeira seditiosa (Keyserling) (Araneae, Araneidae) en condiciones experimentales. Aracnologia Suplemento, Montevideo, 8: 1-9.

WISE, D. H. 1993. Spiders in ecological webs. Melbourne: Cambridge University Press. p. 19-40.

ZAR, J.H. 1999. Biostatistical analysis. Quarta edição. Upper Saddle River, N.J.: Prentice Hall.

Título: Esteriotipia e plasticidade na seqüência predatória de Theridion evexum Keyserling 1884 (Araneae: Theridiidae).

Autores: Carolina Ribeiro Martins Garcia \& Hilton Ferreira Japyassú

Biota Neotropica, Vol. 5 ( número 1a): 2005

http://www.biotaneotropica.org.br/v5n1a/pt/ abstract?article+BN001051a2005

Recebido em 07/12/2003 - Aceito em 01/02/2005

ISSN 1676-0603

\section{Anexo}

\section{Descrição das categorias comportamentais realizadas por $T$. evexum.}

Detecção: movimentos com a região tarsal das pernas anteriores tensionando fios da teia (1-3 mm), com ou sem deslocamento antecedendo tais tensionamentos (Jackson \& Brassington 1987). Esta categoria ocorre no início da captura e tem como função localizar o fio âncora onde a presa está aderida.

Aproximação: deslocamento (frontal) de aproximação da aranha em direção à presa sem tensionamento dos fios de teia. É anterior à captura propriamente dita ocorrendo, portanto, na fase de detecção. A aproximação geralmente é sucedida por toque ou enrolamento de captura (v. abaixo). Viera (1986) descreve uma categoria semelhante denominada “desplazamiento 2", que consiste em um deslocamento da aranha em direção à presa (durante na fase de detecção) o qual pode ser sucedido ou não por um tensionamento do fio. Em sua descrição, Viera não diferencia um deslocamento seguido de tensionamento de fios de um deslocamento simples em direção à presa, categorias que em T. evexum são individualizadas: detecção e aproximação, respectivamente.

Pesca: no lençol ou em um fio âncora (na região próxima ao lençol), a aranha segura com as pernas anteriores o fio âncora onde a presa está aderida e o puxa, com flexões alternadas das pernas I (e ocasionalmente também com as pernas II), de modo a descolar o fio âncora do substrato e trazer a presa para si até que ela esteja entre 1 e $8 \mathrm{~mm}$ de distância para que se inicie o enrolamento de captura (v. abaixo). Em uma variante, a aranha pode puxar vagarosamente um fio que tenha sido previamente descolado pela presa. Em ambos os casos, esta categoria ocorre na fase de detecção e é sucedida por enrolamento de captura. A pesca descrita por Japyassú \& Macagnan (em preparação) é diferente da descrição anterior apenas pelo fato de a aranha tencionar as pernas IV ao invés das pernas I e II (para descolar o fio âncora do substrato) e por ocorrer sempre no lençol.

Enrolamento de captura: após a aproximação e/ou toque com as pernas I a aranha faz um giro de $180^{\circ}$ e direciona o abdome à presa. Com movimentos alternados das pernas IV, a aranha lança sobre a presa fios de seda com gotículas adesivas, na tentativa de imobilizá-la (a aranha se utiliza do pente na perna IV durante a manipulação destes fios de seda - Coddington 1986). O enrolamento de captura é a categoria que determina o início da fase de imobilização, podendo ocorrer também em outros momentos desta fase e na fase de alimentação, porém com menor freqüência.

Enrolamento: o enrolamento é realizado da mesma maneira que o enrolamento de captura, diferindo apenas por serem utilizados fios de seda secos (sem gotículas adesivas). Este tipo de enrolamento apresenta a mesma finalidade do enrolamento descrito por Robinson \& Olazarri (1971) para A. argentata, diferindo apenas pelo volume de fios, que não formam uma "bandagem"; em uma das filmagens foi possível observar que a seda jogada sobre a presa se constitui de apenas três fios simples. Na descrição de Robinson \& Olazarri (1971) a aranha pode ainda movimentar a presa como uma bobina, girando-a sobre um raio enquanto lança seda sobre a presa, com ou sem a ajuda das pernas IV; esta variante de enrolamento não ocorre em T. evexum. 
Manipulação: esta categoria consiste em uma junção de duas categorias já descritas: “toqueteo” (golpes suaves das pernas anteriores e pedipalpos sobre a presa - Viera, 1986), e "manipulate" (pequenas mordidas na presa Robinson 1969). A aranha dá vários toques alternados e consecutivos com os palpos sobre a presa, podendo realizar também mordidas curtas (v. abaixo). Durante a manipulação a aranha pode percorrer pequenas partes do corpo da presa bem como todo ele. Nas capturas de T. evexum, não foram observadas manipulações da presa com as pernas. A manipulação só ocorre após a imobilização da presa. A mordida curta foi incluída no processo de manipulação, devido à dificuldade de diferenciação entre toque de palpos e mordidas curtas.

Mordida curta: inserção e retirada rápida das quelíceras na presa, como se beliscasse a presa (Viera 1986). A mordida curta pode ocorrer nas fases de imobilização e alimentação e, com grande freqüência, permear a manipulação.

Corte de fios: o corte de fios é realizado com as quelíceras. A aranha pode simplesmente aproximar as quelíceras do fio e realizar o corte, ou ainda trazer o fio com as pernas até as quelíceras para então cortá-lo. Esta categoria pode ser executada em vários momentos da captura: antes de iniciar o transporte, cortando os fios ao redor da presa; durante o transporte, cortando fios que estão dificultando seu trajeto; e com a presa no refúgio (Robinson \& Olazarri 1971). Diferente da descrição de Robinson \& Olazarri (1971) para A. argentata, T. evexum não realizou corte de fios com as pernas.

Fixação na presa: a aranha aproxima as fiandeiras da presa, ou dos fios que envolvem esta presa, fixando um novo fio. Viera (1986) descreve uma categoria semelhante a fixação na presa, que é denominada "fijacción de hilos" e ocorre antes do transporte. No presente trabalho, observamos que a fixação na presa também ocorre em outros momentos da captura (fases de imobilização e alimentação).

Retorno: o retorno se dá quando a aranha deslocase em direção ao refúgio. Isto pode ocorrer na fase de deteç̧ão, antes do enrolamento de captura, o que caracteriza um erro de localização da presa (Japyassú \& Macagnan, em preparação). Em T. evexum o retorno foi observado também durante a fase de imobilização da presa, quando então a aranha deixa a presa armazenada temporariamente no lençol ou na periferia da teia.

Estiramento: após o enrolamento, na fase de imobilização da presa, a aranha pode fixar um fio na presa (fixação na presa) ou no fio onde a presa se encontra (fixação - neste caso, a distância entre a presa e a fixação não deve ser maior que um corpo da aranha); após tal fixação a aranha se desloca (ao menos um corpo) em direção ao refúgio, deixando atrás de si um fio guia; a este deslocamento chamamos estiramento. O estiramento pode ocorrer também sem fixação prévia: a aranha interrompe o enrolamento e se desloca imediatamente (ao menos um corpo). Após o estiramento a aranha geralmente fixa no fio de sustentação ou no refúgio, podendo ou não realizar uma pausa (v. abaixo) antes de tal fixação. Quando a aranha estira e fixa, ela pode ainda se deslocar com o mesmo fio, porém já fixado anteriormente, este deslocamento e uma $2^{\mathrm{a}}$ fixação será apenas fixação. O estiramento descrito por Japyassú \& Macagnan (em preparação) difere do descrito acima por não estipular distâncias entre as fixações e os deslocamentos.

Recuperação: a aranha se aproxima frontalmente (região oral) da presa já imobilizada, para retomar as atividades com esta presa (manipulação, enrolamento, corte de fios ao redor da presa, mordidas). Esta aproximação requer um deslocamento da aranha, o qual pode ser muito curto (geralmente após 3fixR - v. abaixo) ou longo, quando então é freqüentemente permeado por outras categorias, como fixação, limpeza ou toques; para fins de registro consideraremos recuperação, nestes casos de deslocamento longo, apenas a última aproximação realizada antes da retomada de atividades com a presa (manipulação, enrolamento, corte de fios ao redor da presa, mordidas). Apesar da recuperação proposta por Viera (1994) apresentar o mesmo nome e a mesma função da descrita acima, ela difere bastante na topografia do movimento. Na descrição de Viera a aranha, no refúgio, puxa para si a presa com o auxílio das pernas I e II. Em T. evexum é a aranha que se desloca em direção à presa, a qual pode ou não estar no refúgio.

Transporte: após fixar na presa (fixação na presa), num fio próximo à ela (fixação) ou após realizar um enrolamento, a aranha desloca-se em direção ao refúgio carregando a presa diretamente nas fiandeiras ou, alternativamente, pendurada nas pernas IV. Robinson \& Olazarri (1971) descrevem dois tipos de transporte: "carry on silk" (igual ao descrito acima) e "carry in jaws”, que consiste no transporte da presa nas quelíceras da aranha (não observado em T. evexum).

Transporte com enrolamento: por julgar necessária a distinção entre transporte simples (como acima), e aquele permeado por enrolamentos, criou-se a categoria transporte com enrolamento, na qual a aranha enrola a presa enquanto a transporta.

Fixações com rotação (3fixR): ao chegar ao refúgio a aranha faz fixações e gira o corpo sagitalmente (Robinson \& Olazarri 1971; Viera 1994).

Pausa: assim como a categoria "quietud", descrita por Viera (1986), a pausa corresponde à imobilidade da aranha. Porém, a categoria pausa deve apresentar uma duração igual ou maior a 30 segundos, diferentemente de "quietud", que independe de tempo para ser determinada. As pausas podem ocorrer nas 3 fases da captura. Na fase de imobilização elas podem ser muito longas, dependendo do tipo e da resistência da presa: quanto mais tempo demorar para a presa parar de se movimentar, mais longas tendem a ser as pausas.

Limpeza: a aranha raspa os apêndices uns nos outros, geralmente aos pares; pode também passar a região tarsal dos apêndices entre as quelíceras; alternativamente, as pernas podem ser raspadas contra o abdome e fiandeiras (Robinson \& Olazarri 1971). A limpeza pode ocorrer nas fases de imobilização e alimentação.

Mordida longa: semelhante à descrição de Viera (1986). 